\title{
МОРФОКИНЕТИЧЕСКИЙ АНАЛИЗ КРИСТАЛЛОВ КВАРЦА
}

Страшненко Г.И.

https://doi.org/10.31241/MIEN.2018.14.14

Екатеринбург, strashnenko_gi@mail.ru

Морфокинетический анализ исследует изменение формы кристаллов в процессе их роста в зависимости от меняющихся физико-химических параметров среды кристаллизации. Целью анализа является получение информации о физико-химических условиях образования минералов по форме их кристаллов. Конечные результаты анализа отражаются графически в виде морфогенетических диаграмм, построенных в координатах «параметр среды кристаллизации - форма кристалла». По определению морфокинетический анализ применим только к комбинационным формам, образованным двумя или более простыми кристаллографическими формами (далее ПКФ).

Изменение формы кристалла происходит путем постепенной смены одних ПКФ, участвующих в его огранении, другими ПКФ. Процесс смены проходит под контролем отношения нормальных (по нормали к плоской грани) скоростей роста граней разных ПКФ $\left(v_{1} / v_{2} / \ldots.\right)$. В процессе роста в огранении кристалла остаются лишь грани ПКФ, характеризующиеся наименьшей скоростью роста относительно других ПКФ. Грани с большей скоростью роста постепенно вырождаются в ребро или вершину кристалла. Вместе с тем для двух ПКФ, участвующих в огранении кристалла, существует интервал значений отношения их скоростей роста, в пределах которого обе ПКФ являются комбинационно устойчивыми и могут при постоянстве условий минералообразования сохраняться достаточно долго. Поэтому на первом шаге анализа необходимо установить границы этого интервала. Эта задача решается геометрически путем нахождения выражения для функции, заданной в общем виде (для случая двойной комбинации):

$$
\Phi=f\left(v_{1} / v_{2}\right),
$$

где Ф-форма кристалла, числено выраженная через площадь его полной поверхности, приведенной к объему, равному 1 ( $F$ - функцию, в формулах просто $F$ ) [9]. Переход от чисто геометрического к кинематическому содержанию $F$ - функции осуществляется путем соответствующей замены независимой переменной в её формуле.

В свою очередь, скорость роста кристалла зависит от пересыщения раствора (переохлаждения расплава, давления насыщенных паров для других агрегатных состояний среды кристаллизации). По результатам экспериментов по искусственному выращиванию кристаллов [13] зависимость эта выражается показательной функцией вида:

$$
v_{i}=k_{i}\left(C_{s}-C_{g}\right)^{n_{i}}
$$


где $C_{s}, C_{g}$ - концентрация насыщения (растворимость) кристаллизующегося вещества соответственно в зоне растворения и зоне роста минералооьразующей системы; $k_{i}, n_{i}$ - постоянные, разные для граней разных ПКФ.

Подставив (2) в (1) получим в общем виде выражение зависимости формы кристаллов от пересыщения для случая двойной комбинации (1/2).

$$
\Phi_{1 / 2}=F_{1 / 2}=f\left[\frac{k_{1}}{k_{2}}\left(C_{S}-C_{g}\right)^{n_{1}-n_{2}}\right]
$$

Пересыщение, в свою очередь, является функцией термодинамических параметров системы: температуры $(t)$, давления $(p)$, химических потенциалов $(\mu)$ подвижных компонентов, в качестве которых могут выступать водородный показатель $(p H)$, окислительно-восстановительный потенциал $(E h)$, активность других ионов, участвующих в минералообразующем процессе.

$$
\Delta C=C_{s}-C_{g}=\varphi(t, p, \mu)
$$

И наконец, подставив (4) в (3) выразим в общем виде функциональную зависимость формы кристалла от термодинамических параметров среды кристаллизации.

$$
F_{1 / 2}=f\left\{\frac{k_{1}}{k_{2}}[\varphi(t, p, \mu)]^{n_{1}-n_{2}}\right\}
$$

Выражение (3) показывает, что форма кристалла какого-либо конкретного минарала однозначно определяется пересыщением. Все иные факторы влияют на его форму опосредовано, изменяя пересыщение (выражение 5).

Основной задачей морфокинематического анализа является нахождение в явном виде функций, входящих в выражения (2-5). Для этого необходимы экспериментальные данные по растворимости минерала и скоростям роста граней разных ПКФ его кристаллов в средах, близких природным. Такие данные имеются только для ограниченного количества минералов. Для тех минералов, для которых экспериментальные данные отсутствуют, можно ограничиться сокращенным анализом, сводимым к нахождению функциональной зависимости для выражения (2). Пример сокращенного (морфокинематического) анализа кристаллов кварца приведен в предшествующей нашей статье в данном сборнике. Кварц самый всесторонне, в том числе и экспериментально, изученный минерал, а потому его кристаллы (горный хрусталь) являются благодатным объектом для полного морфокинетического анализа.

По результататам геологического изучения месторождений горного хрусталя установлены основные закономерности их генезиса. В обобщенном виде эти закономерности ниже сводятся к следующим тезисам.

1. Месторождения горного хрусталя относятся к двум геологическим формациям: хрусталеносных камерных пегматитов и хрусталеносных кварцевых жил. Объединяющим их признаком является рост кристаллов кварца из флюидной или жидкой фазы. 
2. Все значимые месторождения располагаются в одной из двух геологоструктурных позиций: на активизированных архей-нижнепротерозойских щитах (Бразильская, Мадагаскарская, Южно-Якутская и Украинская провинции) и в коллизионных зонах, образованных столкновением островных дуг с пассивной окраиной континента (Уральская, Улутауская провинции) либо столкновением континентальных и субконтинентальных плит (Памирская провинция). Общим объединяющим признаком двух позиций является высокая плотность теплового потока во время их активизации и коллизии. Дополнительным объединяющим признаком является широкое проявление близко одновозрастного гранитного магматизма, вызывающее дополнительное возмущение температурного поля и определяющее его высоко градиентный характер.

3. Температура образования разных месторождений горного хрусталя находится в интервале $200-450^{\circ} \mathrm{C}$, давление флюида 50-100 МПа.

4. Кварц кристаллизуется в открытых полостях, образуя так называемые хрусталеносные гнезда в верхнем горизонте земной коры.

5. Минеральный парагенезис материала гнездового выполнения обычно соответствует минеральному составу вмещающих пород, либо продуктам их реакционного взаимодействия с гидротермами.

6. Кристаллы кварца располагаются в верхней части полости. В новообразованном слое при этом выделяется зона стесненного роста (зона геометрического отбора), книзу постепенно переходящая в зону свободного роста. Вмещающие породы, примыкающие к нижней части полости, несут следы либо выщелачивания породообразующего кварца, либо реакционных процессов с освобождением и выносом в полость кремнезема.

7. Габитусными формами кристаллов кварца являются: положительный ромбоэдр $(r)$, отрицательный ромбоэдр $(\mathrm{z})$ и гексагональная призма $(m)$. Первые две формы являются формами роста, третья -- формой торможения. Как следствие, тело кристалла в основном образовано пирамидами нарастания граней ромбоэдров.

8. В кристаллах кварца обычными являются включения маточного раствора, представляющего жидкую водно-углекислую фазу, иногда с выделением избыточной двуокиси углерода в виде газовой и жидкой фаз. Солевой компонент раствора представлен в основном катионами $\mathrm{Na}^{+}$, в меньшем количестве $\mathrm{K}^{+}$, еще в меньшем $\mathrm{Ca}^{+2}$, анионами $\mathrm{Cl}^{-}, \mathrm{HCO}_{3}^{-}$, редко $\mathrm{SO}_{4}^{-2}$. В ГЖВ иногда встречается также твердая фаза в виде кристалликов галита, сильвина и некоторых других трудно диагностируемых минералов.

9. Совершенные кристаллы растут плоскими гранями. В процессе роста кристаллов наблюдается смена отношения площадей граней разных простых кристаллографических форм. Отношение суммы площадей граней отрицательного ромбоэдра к сумме площадей граней положительного ромбоэдра колеблется от нуля до единицы, на крупных кристаллах оно, как правило, равно единице. 
Выводы, получаемые в результате мофокинетичесого анализа, не должны противоречить содержанию приведенных выше тезисов.

Для начала выполним кинематический анализ изменения формы кристаллов кварца.

Морфокинематический анализ предусматривает изучение изменения формы кристаллов в зависимости от изменения отношения скоростей роста граней ПКФ, участвующих в их огранении. При этом причины (силы), определяющие величины скоростей роста граней, не рассматриваются.

Для расчета предельных значений отношения скоростей, при которых устойчивыми являются те или иные комбинации ПКФ, немецкий кристаллограф Л. Боргстрём применил геометрическую методику. Содержание этой методики изложено в книге Бакли [1]. Сохраняя идею методики Л. Боргстрёма, найдем предельные отношения скоростей роста ромбоэдров $r$ и $z$ кварца иным, более простым способом. На рисунке 1 показаны сечения кристалла кварца по плоскости (10.0) для двух предельных случаев: 1) $v_{z}=v_{r}=1$; 2) $v_{z}>v_{\dot{r}}$ В первом случае очевидно, что кристалл имеет биромбоэдрический (псевдогексагональный) габитус и при постоянстве физико-химических условий может сохранять его бесконечно долго. Во втором случае ромбоэдр $z$ вырожден в точку $z_{0}$, представляющую вершину кристалла, образованную гранью призмы и двумя смежными гранями ромбоэдра $r$.
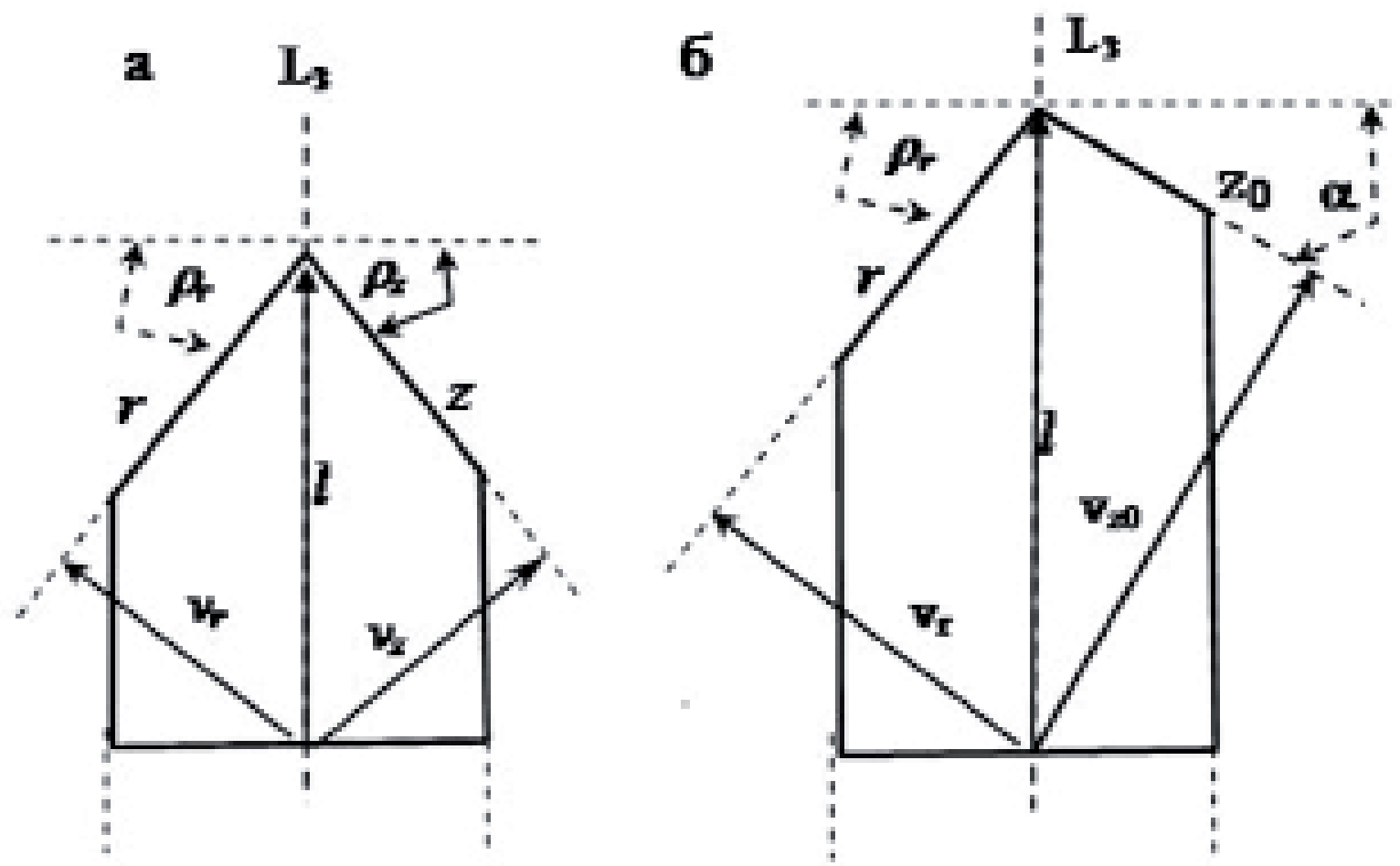

Рис.1. Иллюстрачия к выводу условий роста и вырождения граней положительного (r) и отрицательного (z) ромбоэдров квариа.

Определим геометрические элементы кристалла, участвующие в определении предельного отношения скоростей ромбоэдров для второго случая: $l$ - полудлина по $L_{3}$ полного кристалла; $v_{r}, v_{z}$ - скорости роста граней соот- 
ветствующих ромбоэдров, равные для времени $\tau=1$ нормалям к граням этих ромбоэдров. Заметим, что в обоих случаях принимается, что с момента зарождения до момента $\tau=l v_{r}=$ const, $v_{z}=$ const. Точку $z_{0}$ на рисунке 16 рассматриваем как грань ромбоэдра $z$ размерности 0 . Тогда скорость её роста определяется нормалью к ребру ромбоэдра $r$. Из геометрических отношений элементов кристалла следует (нижний индекс в символах полярных углов упускаем, поскольку для коррелятивных ромбоэдров эти углы равны):

$$
v_{r}=l \operatorname{Cos} \rho ; \quad v_{z}=l \operatorname{Cos} a .
$$

Разделив второе равенство на первое, имеем:

$$
\frac{v_{z}}{v_{r}}=\frac{\operatorname{Cos} \alpha}{\operatorname{Cos} \rho}
$$

В теоретически возможном варианте $v_{z}<v_{r}$ для коррелятивных ромбоэдров будет отношение (2) будет обратным.

$$
\frac{v_{z}}{v_{r}}=\frac{\operatorname{Cos} \rho}{\operatorname{Cos} \alpha}
$$

Очевидно, что интервал, определяемый предельными отношениями скоростей граней (2) и (3) охватывает все теоретически возможные габитусы головок кристалла, образованных ромбоэдрами $r$ и $z$. Подставив в выражения (2) и (3) значение углов $\rho=51.79^{\circ} ; \alpha=26.54^{\circ}$, получим интервалы существования ромбоэдров в огранении кристаллов кварца по критерию отношения скоростей роста их граней.

$$
\begin{gathered}
\frac{v_{z}}{v_{r}}<0,692 \quad \Leftrightarrow \quad 0,692 \leq \frac{v_{z}}{v_{r}} \leq 1,446 \quad \Leftrightarrow \quad \frac{v_{z}}{v_{r}}>1,446 \\
z\{01.1\} \quad \Leftrightarrow \quad r\{10.1\}+\{01.1\} \quad \Leftrightarrow r\{10.1\}
\end{gathered}
$$

На полученное теоретически выражение (4) накладывается ограничение, вытекающее из тезиса 9. В результате (4) преобразуется в (5), в котором $S$ - площадь грани.

$$
\begin{gathered}
1 \leq \frac{v_{z}}{v_{r}} \leq 1,446 \Leftrightarrow \frac{v_{z}}{v_{r}}>1,446 \\
r\{10.1\}+\{01.1\} \\
\begin{array}{c}
\Sigma S_{r} \geq \Sigma S_{z}
\end{array}
\end{gathered}
$$

По методике Л. Боргстрёма левая граница устойчивости двух смежных граней кристаллов равна $v_{1} / v_{2}=\operatorname{Cos} \beta$, правая $-v_{1} / v_{2}=1 / \operatorname{Cos} \beta$, где $\beta-$ двухгранный угол, образованный этими гранями. Для кварца $\beta_{r_{z}}=46.25^{\circ}$ [4]. Подставив его в приведенные выше равенства, получим те же значения границ интервала сосуществования ромбоэдров $z$ и $r$, что и в выражении (4).

В заключение морфокинематического анализа кратко остановимся на особенностях роста граней гексагональной призмы. В соответствии с тезисом 7 на природных кристаллах кварца $v_{m}=0$. Наблюдаемые пирамиды на- 
растания граней призмы, как правило, являются ложными, поскольку они образованы слоями роста острых ромбоэдров. Грани призмы появляются обычно у корневой части кристалла и тангенциально разрастаются за счет вырождения граней острых ромбоэдров. Когда они достигают головки кристалла, скорость их тангенциального разрастания прямо зависит от скорости роста основных ромбоэдров. При этом утолщение кристалла прекращается, а его длина по третьей оси при достаточном объеме природного кристаллизатора определяется длительностью процесса кристаллизации и не зависит от его физико-химических условий. Толщина кристалла определяется площадной плотностью потенциальных зародышей, оптическая ось которых ориентирована перпендикулярно стенке, на которой нарастают кристаллы. Следовательно, такой широко используемый в производственной практике параметр кристалла, как удлинение, не несет интересующей нас сущностной генетической информации.

Далее проанализируем результаты экспериментальных работ по растворению кварца и росту его кристаллов. Такого рода работы широко проводились во Всесоюзном научно-исследовательском институте синтеза минерального сырья (ВНИИСИМС) в связи с проблемами гидротермального синтеза кристаллов и возможности экстраполяции полученных выводов на природный процесс $[2,3]$. Сначала рассмотрим результаты исследования растворимости кварца в водно-солевых растворах, по составу близких к природным (тезис 7).

На рисунке 2 приведены графики растворимости кварца в зависимости от температуры, давления и концентрации содового раствора. Давление при этом задавалось коэффициентом заполнения автоклава. Маркерами на графиках показаны значения растворимости кварца, определенные экспериментально в интервале температур от 280 (для $2 \%$-го раствора $\mathrm{Na}_{2} \mathrm{CO}_{3}$ ) и 340 до $480^{\circ} \mathrm{C}$ (для $5 \%$ и $11 \%$-го раствора $\mathrm{Na}_{2} \mathrm{CO}_{3}$ ) [2]. В область более низких температур (до $200^{\circ} \mathrm{C}$ ) и более высоких концентраций минерализатора, допускаемыми тезисами 3,7 , результаты экспериментов экстраполированы показательными функциями (показаны в левом верхнем углу рисунка 2).

В общем виде зависимость растворимости кварца в водно-солевом растворе от температуры при постоянных давлении $(p)$ и концентрации соли $(s)$ выражается степенным уравнением вида:

$$
\left.\frac{d C}{d t}\right|_{\substack{p=\text { const } \\ s=\text { const }}}=k_{s} m_{s} t^{m_{s}-1}
$$

При температуре $t_{1}$ в зоне растворения и $t_{2}$ в зоне роста $\left(t_{1}>t_{2}\right)$ пересыщение раствора кремнеземом при постоянном давлении и концентрации солей составит

$$
\Delta C \mid \begin{gathered}
p=\text { const } \\
s=\text { const }
\end{gathered}=k m_{s} \int_{t_{2}}^{t_{1}} t^{m_{s}-1} d t=k_{s}\left(t_{1}^{m_{s}}-t_{2}^{m_{s}}\right)
$$




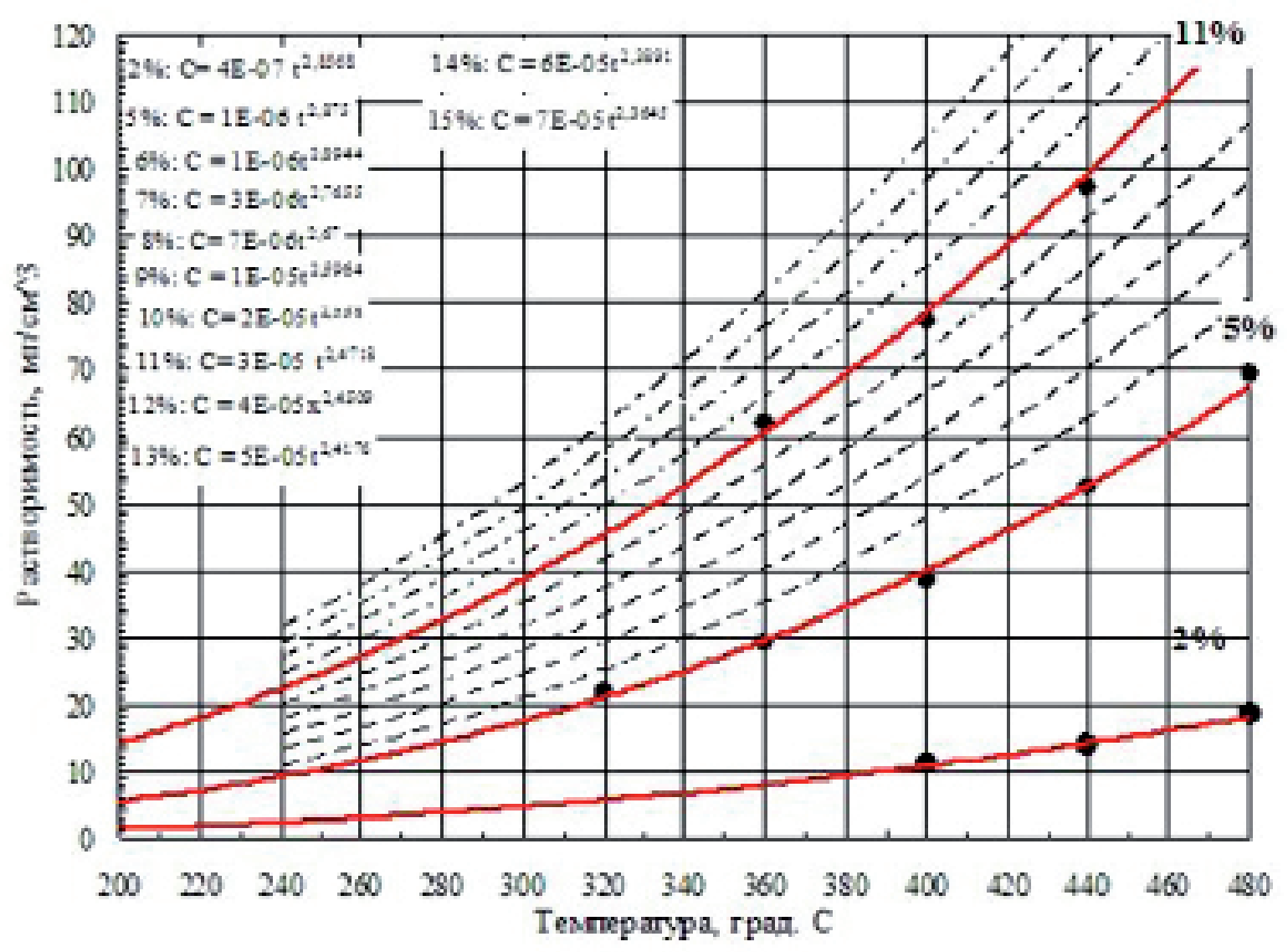

Рис. 2. Зависимость растворимости квариа от температуры в водно-содовом растворе при различной концентрации $\mathrm{Na}_{2} \mathrm{CO}_{3}$ и коэффичиенте заполнения автоклава $70 \%$.

Маркерами показаны экспериментальные данные, аппроксимация, интерполяция и экстраполяиия экспериментальных данных в область низких температур и высоких концентраций соли проведены автором.

Из уравнения (7) следует, что пересыщение гидротермальных растворов кремнеземом при постоянной концентрации минерализатора $(s)$ зависит не только от перепада температуры между зоной растворения и зоной роста, но и от абсолютного значения самой температуры. Графики $\Delta C=f(t)$, построенные по формуле (7), приведены на рисунке 3 для разных температурных перепадов. Они показывают, что при фиксированном температурном перепаде $(\Delta t)$ пересыщение, а следовательно и скорость роста кристаллов, повышаются с ростом температуры процесса.

Экспериментально доказано, что эффективное растворение кварца достигается в щелочных гидротермальных растворах [2]. Поддержание необходимой щелочности $(p H)$ достигается введением в раствор минерализаторов, в качестве которых выступают гидроокись или карбонат натрия (сода). Подщелачивание раствора в первом случае происходит за счет диссоциации гидроокиси, а во втором - за счет гидролиза карбонат-иона по схеме: $\mathrm{CO}_{3}^{-2}+\mathrm{H}_{2} \mathrm{O} \rightarrow+\mathrm{HCO}_{3}^{-}+\mathrm{OH}^{-}$. 


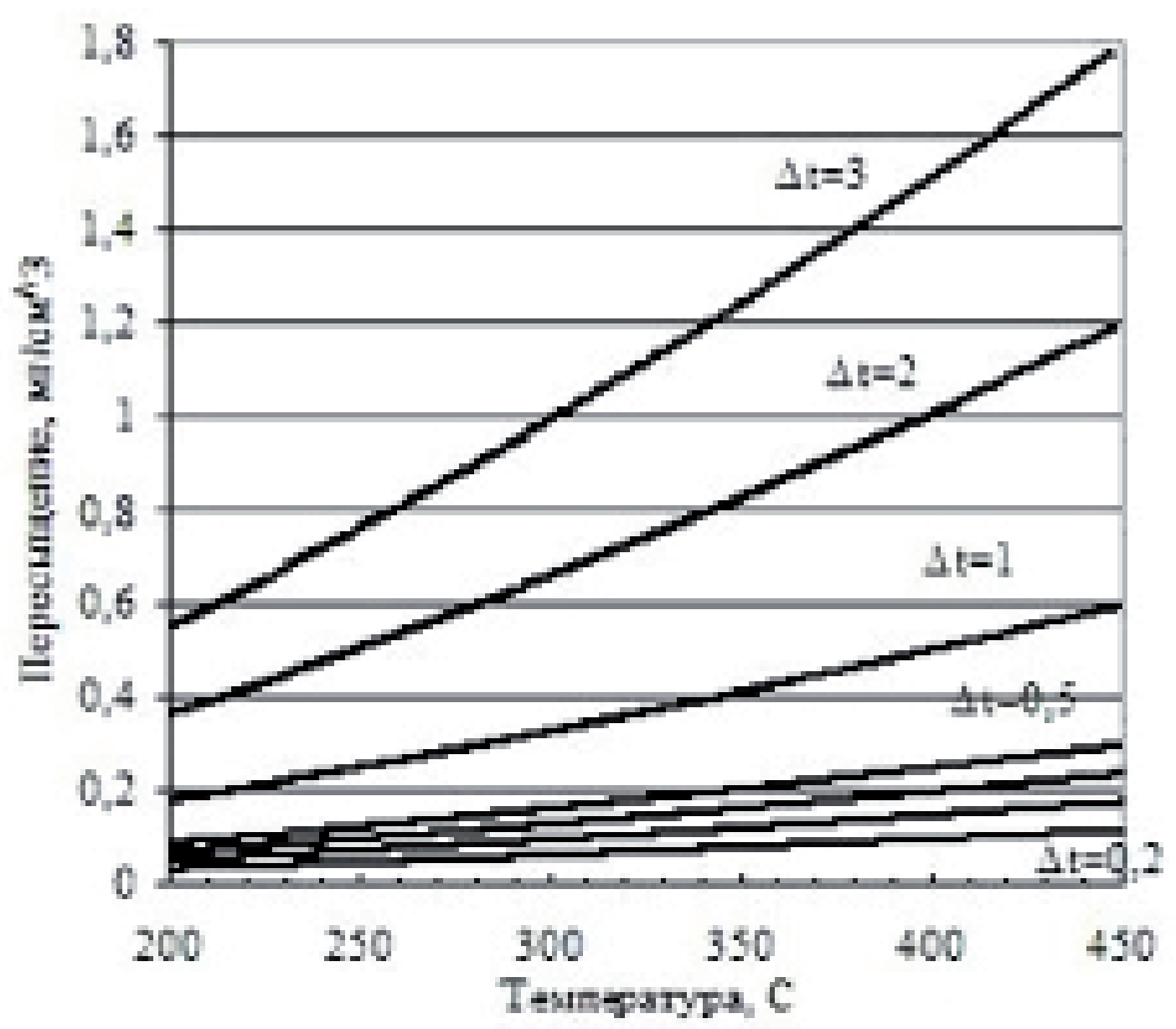

Рис. 3. Зависимость пересыщения кремнеземом водно-содовых гидротермальных растворов от температуры. Концентрация соды в растворе $11 \%$.

Рассмотрим зависимость растворимости кварца от концентрации $(s)$ соды в гидротермальном растворе при постоянной температуре. На рисунке 2 видно, что с повышением концентрации соды растворимость кварца растет. Рассмотрим эту зависимость более детально. Графики изотерм растворимости кварца $\underset{t=c o n s t}{C}=f\left(s_{\mathrm{Na}_{2} \mathrm{CO}}\right)$ представлены на рисунке 4. Черными маркерами на графиках показаны экспериментальные данные [2], полученные в интервале температур от 360 до $480^{\circ} \mathrm{C}$. Положение красных маркеров определено аппроксимацией зависимости $C=f(t)$ в область температур ниже $360^{\circ} \mathrm{C}$. Рассматривая эти графики (рис. 4), можно видеть, что при постоянной температуре выше $320^{\circ} \mathrm{C}$ растворимость кварца в зависимости от концентрации соды в растворе изменяется по закону, аппроксимируемому квадратичными функциями вида

$$
\underset{t=\text { const }}{C}=k s^{2}+l s+m
$$

при температуре ниже $320^{\circ} \mathrm{C}$ эта зависимость ближе к линейной

$$
\underset{t=\text { const }}{C}=k s+l
$$

где $k, l, m$ - постоянные коэффициенты. 
Уравнения изотерм растворимости кварца, рассчитанные по экспериментальным и экстраполированным данным, показаны в левом верхнем углу рисунка 4.

Из (8) и анализа графиков (рис. 4) следует, что пересыщение раствора кремнеземом при постоянной температуре выше $320^{\circ} \mathrm{C}$ зависит не только от разности концентрации соды в зонах растворения и роста, но и от самой её концентрации в растворе. т.е. при постоянной температуре равно разности значений квадратичной функции (8) при изменении концентрации соды от $s_{1}$ до $s_{2}$.

$$
\underset{t>320^{0} C=\text { const }}{\Delta C}=k\left(s_{2}^{2}-s_{1}^{2}\right)+l\left(s_{2}-s_{1}\right),
$$

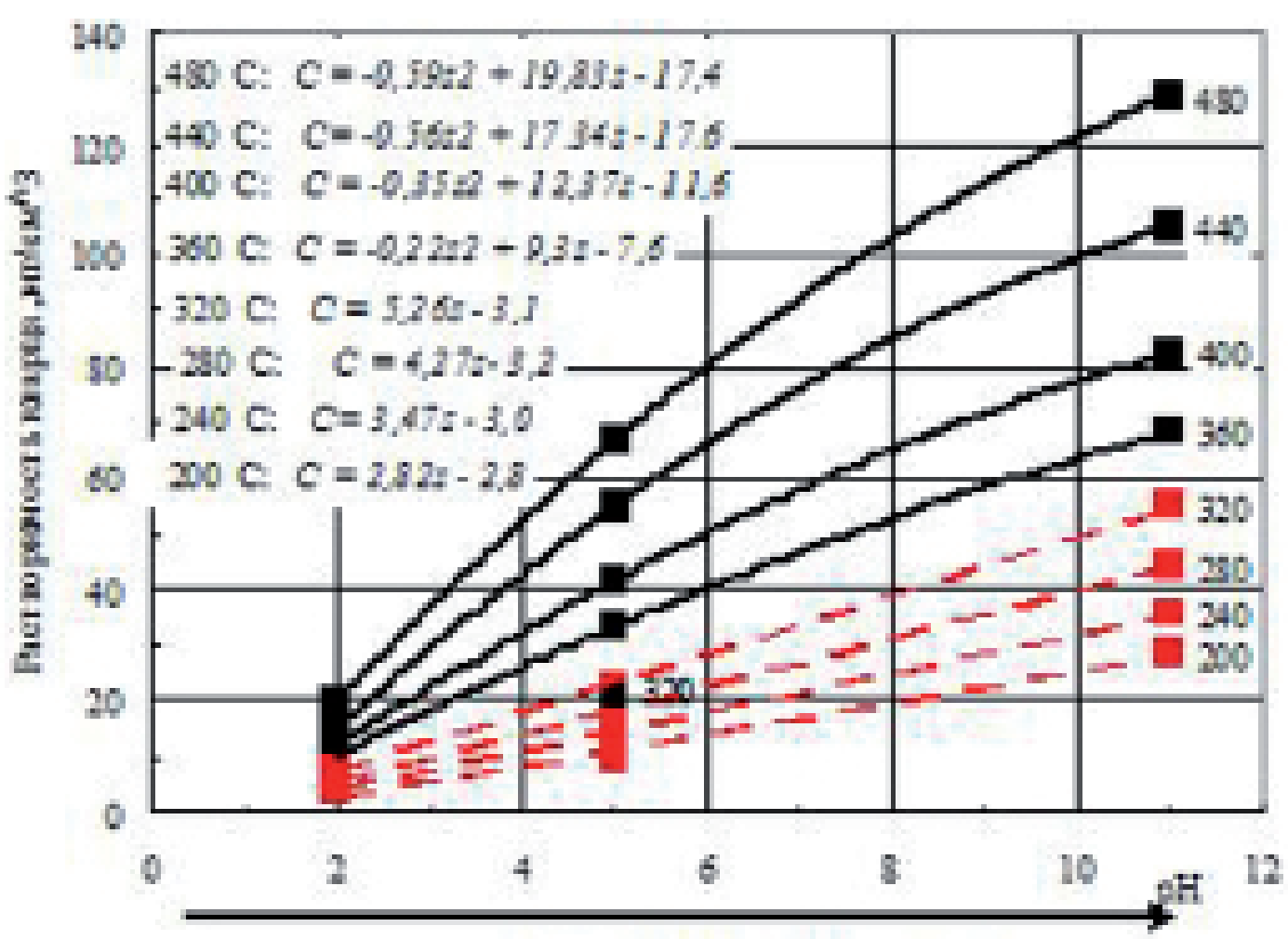

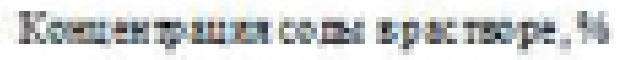

Рис. 4. Изотермы растворимости квариа в содовом гидротермальном растворе.

Графики функция (8) показывают, что с ростом концентрации соды в растворе скорость растворения кварца снижается и достигнув определенного минимума, может принять ретроградный характер. Критические значения концентрации соды определяются анализом уравнения (8). На рисунке 5 представлены графики изотерм скорости растворения кварца, полученные дифференцированием уравнений квадратичных функций, показанных на рисунке 4. Точка пересечения изотерм с осью абсцисс дает критическое значение концентрации соды, после которого процесс растворения принимает ретроградный характер. Снижение температуры сдвигает критическую точку вправо, в сторону больших концентраций минерализатора. 
В низкотемпературной области $\left(\leq 320^{\circ} \mathrm{C}\right)$ зависимость растворимости кварца от концентрации минерализатора принимает линейный характер. Скорость растворения в этом случае зависит только от разности концентраций минерализатора в зонах растворения и роста. На рисунке 5 изотермы скорости растворения, а следовательно и возможного пересыщения раствора кремнеземом, представляют прямые, параллельные оси концентраций.

На основании проведенного анализв экспериментальных данных можно заключить, что процесс кристаллизации кварца в крупных гидротермальных системах, в которых расстояние между зонами растворения и роста достигает десятков метров, проходит под контролем перепада температуры. Достижение пересыщения раствора кремнеземом описывается при этом формулой (7). В мелких системах (минерализованных трещинах), в которых $\Delta t \rightarrow 0$ процесс управляется изменением щелочности растворов $(\mathrm{pH})$ в результате их взаимодействия с вмещающими породами в ближнем околотрещинном пространстве. Пересыщение при этом определяется квадратичной функцией от концентрации минерализатора для $t>320^{\circ} \mathrm{C}(10)$ и линейной функцией (рис. 4) для $t \leq 320^{\circ} \mathrm{C}$.

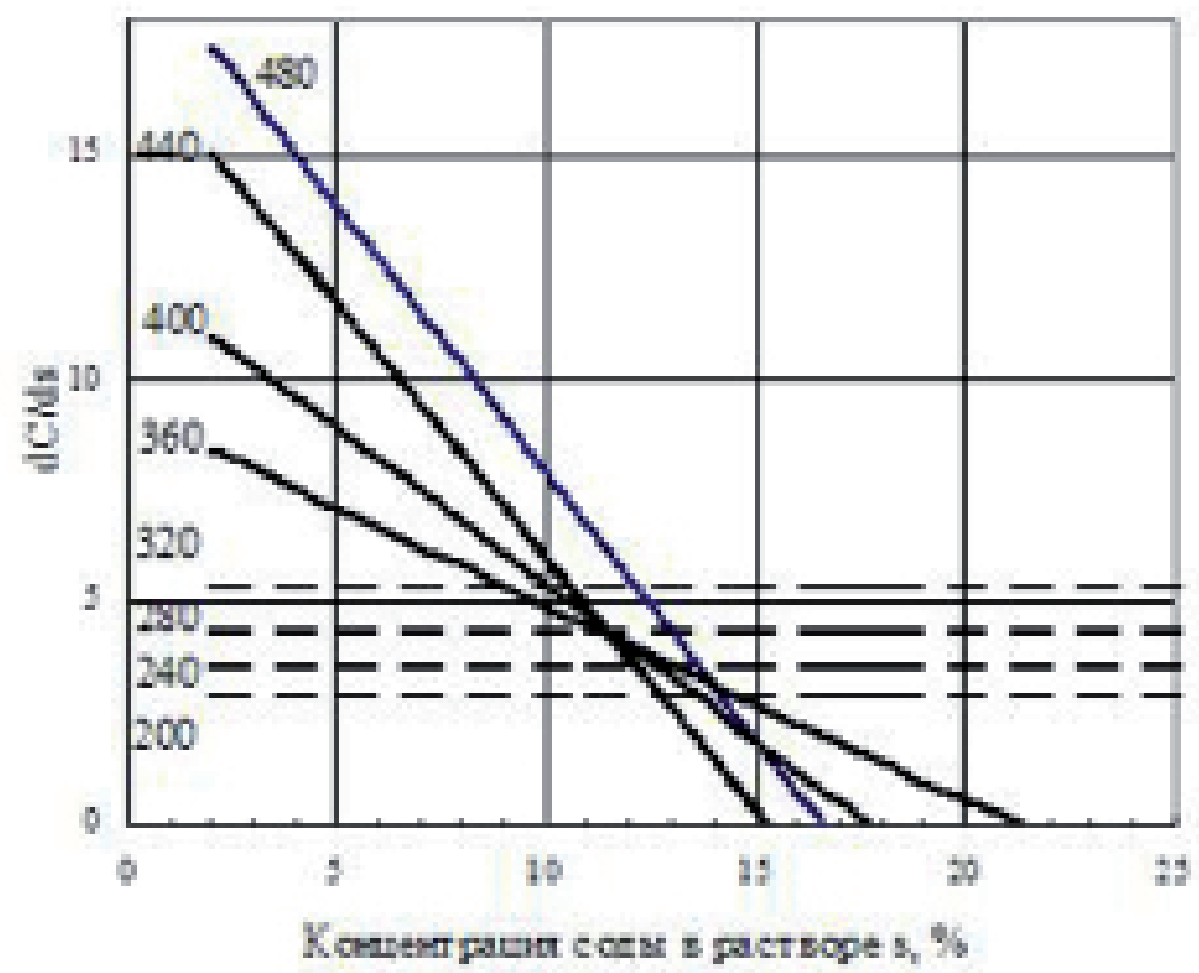

Рис. 5. Изотермы скорости растворения квария в содовом гадротермальном растворе.

Далее перейдем к анализу экспериментальных данных по кинетике роста граней разных ПКФ кварца, полученных во ВНИИСИМС'е группой В.С. Балицкого [2]. Исследования проводились в опытном автоклаве методом температурного перепада в разных средах, при разных температурах и при разном коэффициенте заполнения автоклава. Пересыщение раствора кремнеземом при этом учитывалось косвенным образом через перепад тем- 
пературы $(\Delta t)$ между зонами растворения и роста кварца. Скорость роста граней разных ПКФ кварца изучалась в интервале перепадов от 280 до $400^{\circ} \mathrm{C}$ при $\Delta t$ от 5 до $40^{\circ} \mathrm{C}$. Результаты опытов отражались на графиках, построенных в координатах $v=f(\Delta t)$.

Для анализа полученных данных и определения возможности их экстраполяции на природный процесс нами выбраны результаты опытов, полученные при параметрах автоклава, максимально приближенных к природному процессу (тезисы 3 и 8): температура $330^{\circ} \mathrm{C}$ и 5 \%, 11 \% раствор соды, коэффициент заполнения автоклава 70 \%, что примерно соответствует давлению 100 МПа. При этих параметрах и принятых в экспериментах перепадах температуры скорость роста основных ромбоэдров подчиняется линейному закону (рис. 6).

$$
\begin{aligned}
& v_{z}=0.032(\Delta t)-0.08 \\
& v_{r}=0.016(\Delta t)-0.224
\end{aligned}
$$

Экстраполировать полученные результаты на природный процесс образования хрусталеобразования нельзя по двум причинам.

1. Использованные в эксперименте перепады температуры при высоте автоклава 2м дают значения геотермического градиента от 2500 до $20000^{\circ} \mathrm{C} /$ км, что для земной коры является очевидным нонсенсом.

2. Отношение $v_{z} / v_{r}$ при $\Delta t=16.8^{\circ} \mathrm{C}$ равно 11.9 , что значительно превышает верхний предел (1.45) сосуществования основных ромбоэдров. Ниже $\Delta t=16.8^{\circ} \mathrm{C}$ отношение рассматриваемых скоростей возрастает до бесконечности. Если экстраполировать используемые перепады температуры на природные объекты, то

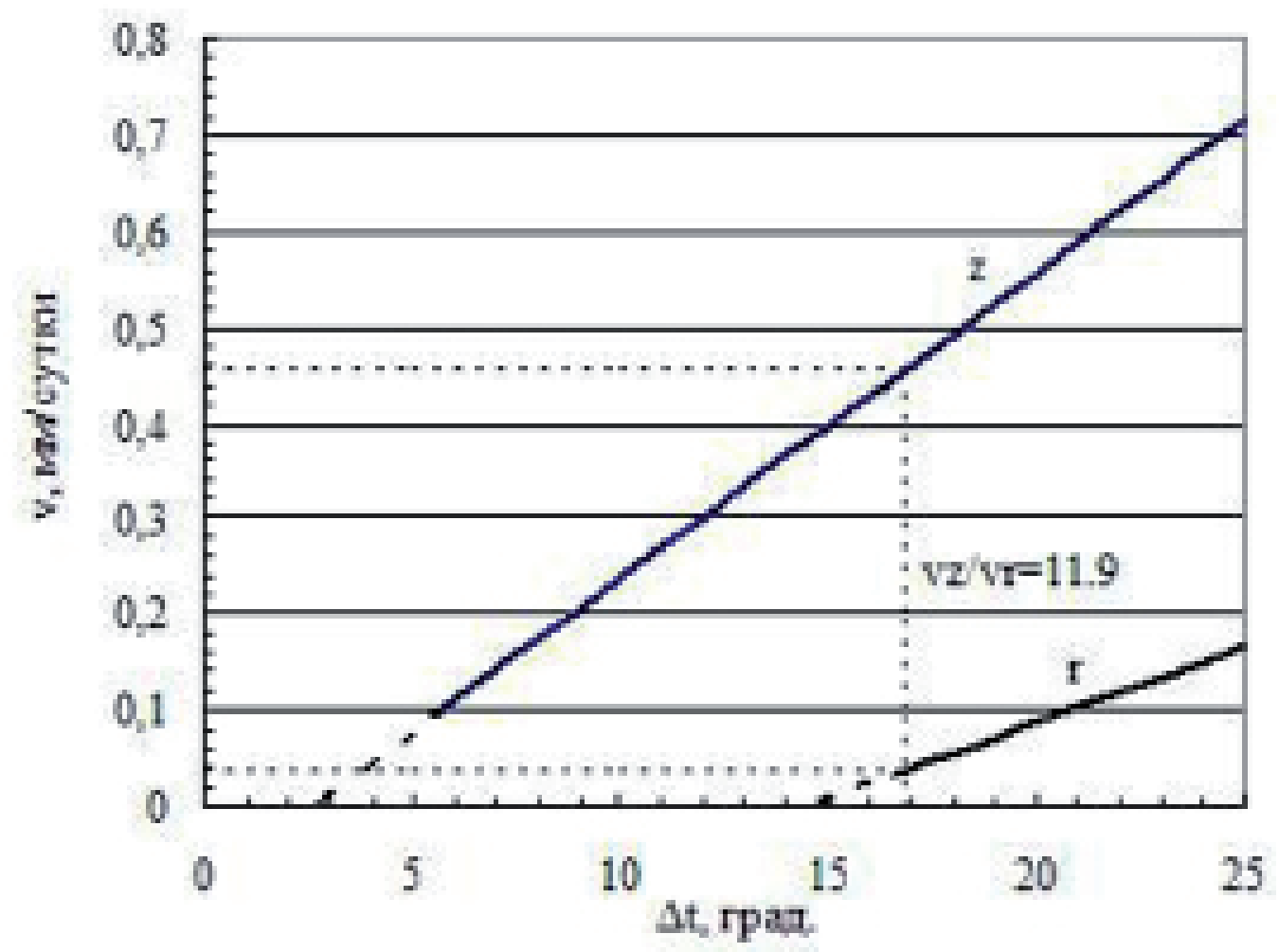

Рис. 6. Зависимость скорости роста граней основных ромбоэдров квариа от температурного перепада в зонах растворения и роста (по экспериментальнылм данным [2]). 
в соответствии с (5) головки кристаллов кварца должны быть образованы только гранями положительного ромбоэдра, что противоречит тезисам 7 и 9. Действительно, если посмотреть выложенные в Интернете многочисленные фото регенерированных в автоклаве битых кристаллов кварца, то можно видеть, что в огранении их головок резко преобладают грани положительного ромбоэдра над гранями отрицательного. Если процесс продолжался ещё бы какое-то время, то грани отрицательного ромбоэдра выродились бы полностью.

Из 1 и 2 следует, что природный процесс хрусталеобразования происходит при пересыщениях, значительно меньших, чем применяемые в экспериментах В.С. Балицкого и в промышленном синтезе пьезооптического кварца. При очень слабых пересыщениях гидротермальных растворов скорость роста кристаллов должна подчиняться закону высшего порядка и кинетические кривые роста ромбоэдров должны иметь точку пересечения в соответствии с (5) и тезисом 9. Далее перейдем собственно к морфокинетическому анализу.

Стрикленд-Констэбл Р.Ф. показал, что при слабых пересыщениях имеет место закон высшего порядка, по которому скорость роста кристаллов описывается степенной функцией (2), в которой $n>1$. График этой функции должен представлять кривую, асимптотически приближающуюся к оси пересыщений в начале координат и переходящую в прямую при высоких пересыщениях. Линейная часть кривой при её продолжении не проходит через начало координат, что и подтверждается экспериментально (рис. 11). По заключению Р.Ф. Стрикленд-Констэбл такого рода кривые часто встречаются при кристаллизации из жидкой фазы.

Определим вид функции (2) для основных ромбоэдров кварца. Для этого запишем для каждого из них.

$$
\begin{aligned}
& v_{z}=k_{z}(\Delta C)^{n_{z}} \\
& v_{r}=k_{r}(\Delta C)^{n_{r}}
\end{aligned}
$$

Подставив (7) в (13) и (14), получим уравнения, описывающие скорости роста основных ромбоэдров в зависимости от параметров хрусталеобразующего процесса.

$$
\begin{gathered}
v_{z}=k_{z} k_{s}^{n_{z}}\left(t_{1}^{m_{S}}-t_{2}^{m_{s}}\right)^{n_{z}} \\
v_{r}=k_{r} k_{s}^{n_{r}}\left(t_{1}^{m_{S}}-t_{2}^{m_{s}}\right)^{n_{r}}
\end{gathered}
$$

В формулах $(15,16)$ :

$v_{z}, v_{r}$-скорости роста граней основных ромбоэдров, мм/сутки;

$k_{z}, k_{r}$ - кинетические коэффициенты основных ромбоэдров, мм/сутки ${ }^{-1}$ град. ${ }^{-n}$;

$k_{s}, m_{s}$ - коэффициент и показатель степени, зависящие от концентрации соли в растворе (или $p H$ раствора);

$t_{l}, t_{2}$ - температура соответственно в зоне растворения и в зоне роста кварца, ${ }^{\circ} \mathrm{C}$; $n_{z}, n_{r}-$ показатели степени для основных ромбоэдров. 
В уравнениях (15) и (16) не известны кинетические коэффициенты $k_{z}, k_{r}$ и показатели степенной функции $n_{z}, n_{r}$ Строго математически определить их невозможно из-за недостаточности экспериментальных данных. Попытаемся оценить их приблизительно, опираясь на экспериментальные данные В.С. Балицкого [2] и Р.Ф. Стрикленд-Констэбл [13], а также на выводы, полученные выше морфокинематическим анализом (5). Уравнения (15) и (16) должны удовлетворять следующим условиям и допущениям:

1. $n_{z}>n_{r}$ в соответствии с тезисом 9 .

2. Иметь одну общую точку в поле положительных пересыщений, в которой согласно тезису $9 v_{z}=v_{r}$. Последнее равенство реализуется при $n_{z}-n_{r}=1$.

3. Удовлетворять выражению (5) на границах сосуществования ромбоэдров.

4. $1.5 \leq n \leq 2.5$ в соответствии с экспериментальными данными, полученными Р.Ф. Стрикленд-Констэбл, на основании измерения скоростей роста кристаллов легко и слабо растворимых в воде веществ при температуре от 25 до $70^{\circ} \mathrm{C}[13]$.

5. Допущению, чтопереходростаромбоэдровотлинейногозаконакзаконувысшего порядка осуществляется при минимальных перепадах температуры, использованных в эксперименте В.С. Балицкого (рис. 6$): z\left(5.6^{\circ} \mathrm{C} ; 0.1 \mathrm{mм} / \mathrm{cym \kappa и}\right)$; $r\left(16.8^{\circ} \mathrm{C} ; 0.037\right.$ мм/сутки $)$.

Методом перебора возможных вариантов установлено, что наиболее полно удовлетворяются сформулированные выше условия при $n_{z}=2.4$ и $n_{r}=1.4$. Подставив их в формулы (15) и (16) для температуры в зоне роста $330^{\circ} \mathrm{C}$ и концентрации соды $11 \%\left(k_{s}=3 \cdot 10^{-5} ; m_{s}=2.4718\right.$, получим два уравнения с двумя неизвестными:

$$
\begin{gathered}
0.1=k_{z}\left(3 \cdot 10^{-5}\right)^{2.4}\left(335.6^{2.4718}-330^{2.4718}\right)^{2.4} \\
0.037=k_{r}\left(3 \cdot 10^{-5}\right)^{1.4}\left(346.8^{2.4718}-330^{2.4718}\right)^{1.4}
\end{gathered}
$$

Решив данные уравнения, определим кинетические коэффициенты: $k_{z}=0.0161 ; k_{r}=0.0026$. Поскольку скорость роста кристалла прямо зависит от пересыщения раствора, а другие факторы, как-то температура, давление и химизм раствора, влияют на неё косвенно через изменение пересыщения, величины кинетические коэффициенты принимаются постоянными при любых значениях указанных факторов. Подставив в (29-30) найденные величины постоянных получим уравнения для построения морфогенетических графиков.

$$
\begin{aligned}
& v_{z}=0.161(\Delta C)^{2.4}=0.0161 k^{2.4}\left(t_{2}^{m}-t_{l}^{m}\right)^{2.4} \\
& v_{r}=0.026(\Delta C)^{1.4}=0.0026 k^{1.4}\left(t_{2}^{m}-t_{l}^{m}\right)^{1.4}
\end{aligned}
$$

Разделив (17) на (18) получим

$$
\frac{v_{Z}}{v_{r}}=6.085(\Delta C)=6.085 k\left(t_{2}^{m}-t_{1}^{m}\right)
$$

Из выражения (19) получим формулу для определения температуры в зоне растворения при заданных температуре и концентрации раствора в зоне роста. 


$$
t_{1}=\left[t_{2}^{m}+0.16\left(\frac{v_{z}}{k v_{r}}\right)\right]^{\frac{1}{m}}
$$

Выражение (20) может быть полезным для оценки палеогеотермического градиента по оцениваемой в поле высоте хрусталеобразующей системы.

На рисунке 7 показана зависимость скорости роста граней положительного $(r)$ и отрицательного $(z)$ ромбоэдров кварца от пересыщения гидротермального раствора, рассчитанная по формулам (7) и (18). Можно видеть, что кривые роста полностью удовлетворяют приведенным выше условиям. Сверху на рисунке показана шкала отношения $v_{z} / v_{r}$.

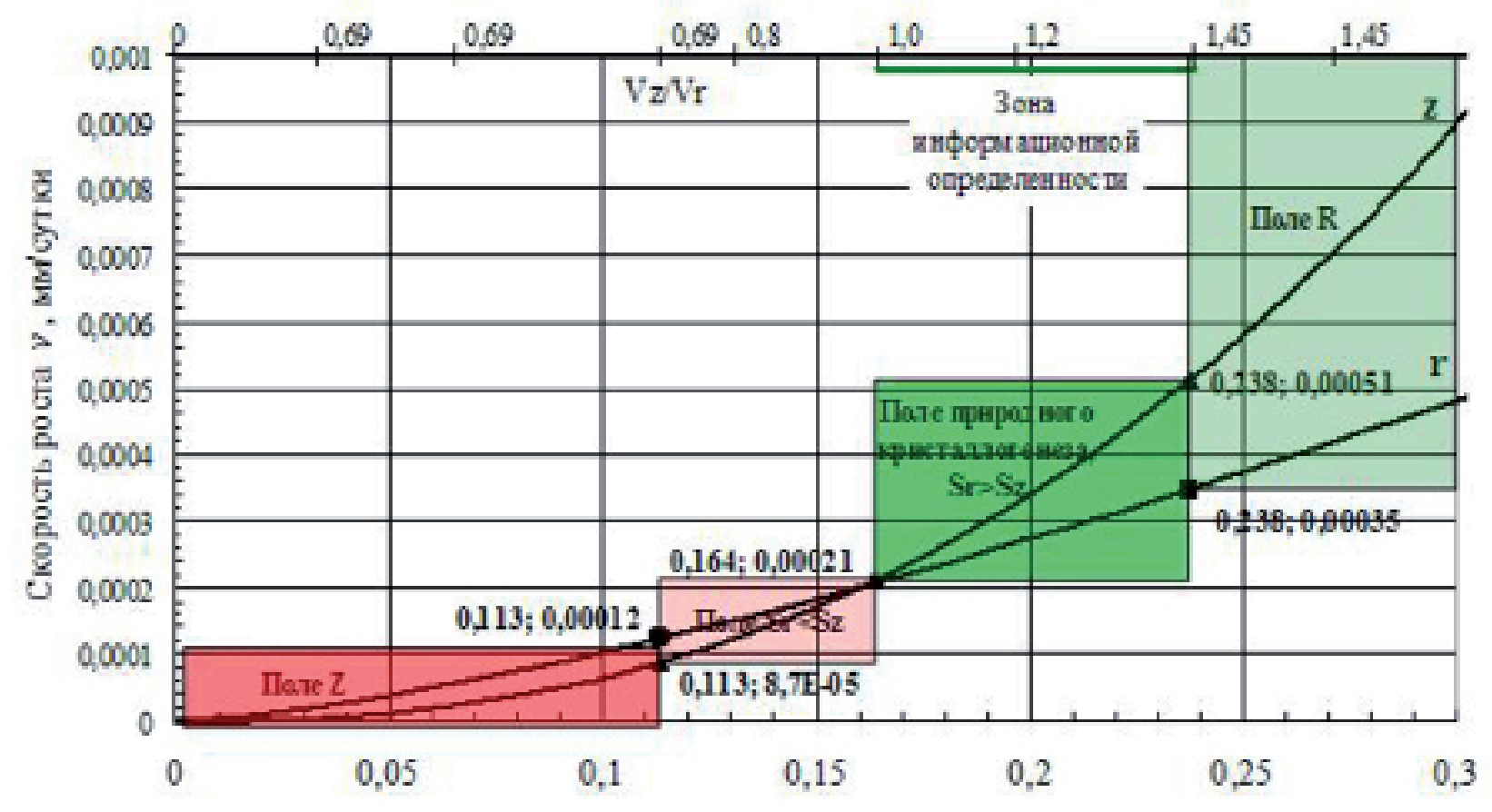

Пересышение $\Delta \mathrm{C}, \mathrm{Mr} / \mathrm{M} 3$

Рис. 7. Скорость роста граней основных ромбоэдров кварйа при мальх пересыщениях гидротермального раствора.

В соответствии с тезисом 9 и границами (4) и (5) на рисунке 12 выделены поля существования разных морфологических типов кристаллов кварца. Слева направо выделены четыре поля: 1) $Z$ - головки кристаллов образованы гранями только ромбоэдра $z$; 2) $S z>S r$ - поле сосуществования двух ромбоэдров, в котором площадь граней $z$ больше площади граней $r$; 3) $S z<S r$ - поле сосуществования двух ромбоэдров, в котором площадь граней $z$ меньше площади граней $r$; 4) $R$ - головки кристаллов образованы только гранями ромбоэдра $r$. Первые два поля выделены лишь теоретически, в природе они не встречаются. Третье и четвертое поля, закрашенные в различные тона зеленого цвета, являются областью 
реального природного кристаллогенеза кварца. Третье поле, заключенное в границах $1 \leq v_{z} / v_{r} \leq 1.45$, является зоной информационной определенности. Только в пределах этого поля морфологические параметры кристалла могут быть математически связаны с физико-химическими условиями его кристаллизации. Четвертое поле является областью информационной неопреленности. Оно открыто вправо. По форме его кристаллов можно определить только нижний предел пересыщения гидротермального раствора.

Графики на рисунке 6 могут быть использованы для оценки пересыщения и скорости роста кристалла, если имеется его анатомическая картина. Когда это невозможно, эти параметры можно оценить по конечной форме кристаллов с использованием его $F$-функции. Для кристалла кварца, образованного комбинацией гексагональной призмы и двух коррелятивных ромбоэдров, с приведенным удлинением призматической части, равным $0.8, F$-функция имеет вид [13]:

$$
F=\left\{6.06+0.58\left[1-(1-y)^{3}\right]\right\}^{-\frac{2}{3}}\left\{18+2\left[1-(1-y)^{2}\right]\right\}
$$

где $y$-доля ребра между двумя смежными гранями положительного ромбоэдра в общей его длине, возможной в случае моноромбоэдрического габитуса головки кристалла: $0 \leq y \leq 1 ; \rho-$ полярная координата граней ромбоэдров; $\alpha$ - полярная координата ребра между двумя смежными гранями положительного ромбоэдра.

Запишем отношение между значениями параметра $y$ и пересыщением на границах поля совместимости обоих ромбоэдров (на рис. 7 первая координата граничных точек):

$$
\begin{array}{llll}
y: & 0 & - & 1 \\
\Delta C: & 0,164 & - & 0,238
\end{array}
$$

В отношении (22) оба параметра в указанных пределах изменяются линейно. Решив линейное уравнение, составленное по координатам (22), произведем в (21) замену переменной:

$$
y=\frac{\Delta C-0.164}{0.074}
$$

С учетом новой переменной (21) преобразуется к виду:

$$
F=\left\{6.06+0.58\left[1-\left(1-\frac{\Delta C-0.164}{0.074}\right)^{3}\right]\right\}-\left(\frac{2}{3}\right)\left\{18+2,\left[1-\left(1-\frac{\Delta C-0.164}{0.074}\right)^{2}\right]\right\}
$$

Рассчитанный по формуле (24) график (рис. 8) позволяет по форме кристалла, его $F$-функции, оценить пересыщение гидротермального раствора.

Проиллюстрируем использование морфокинетического анализа для решения ряда минерагенических задач. 


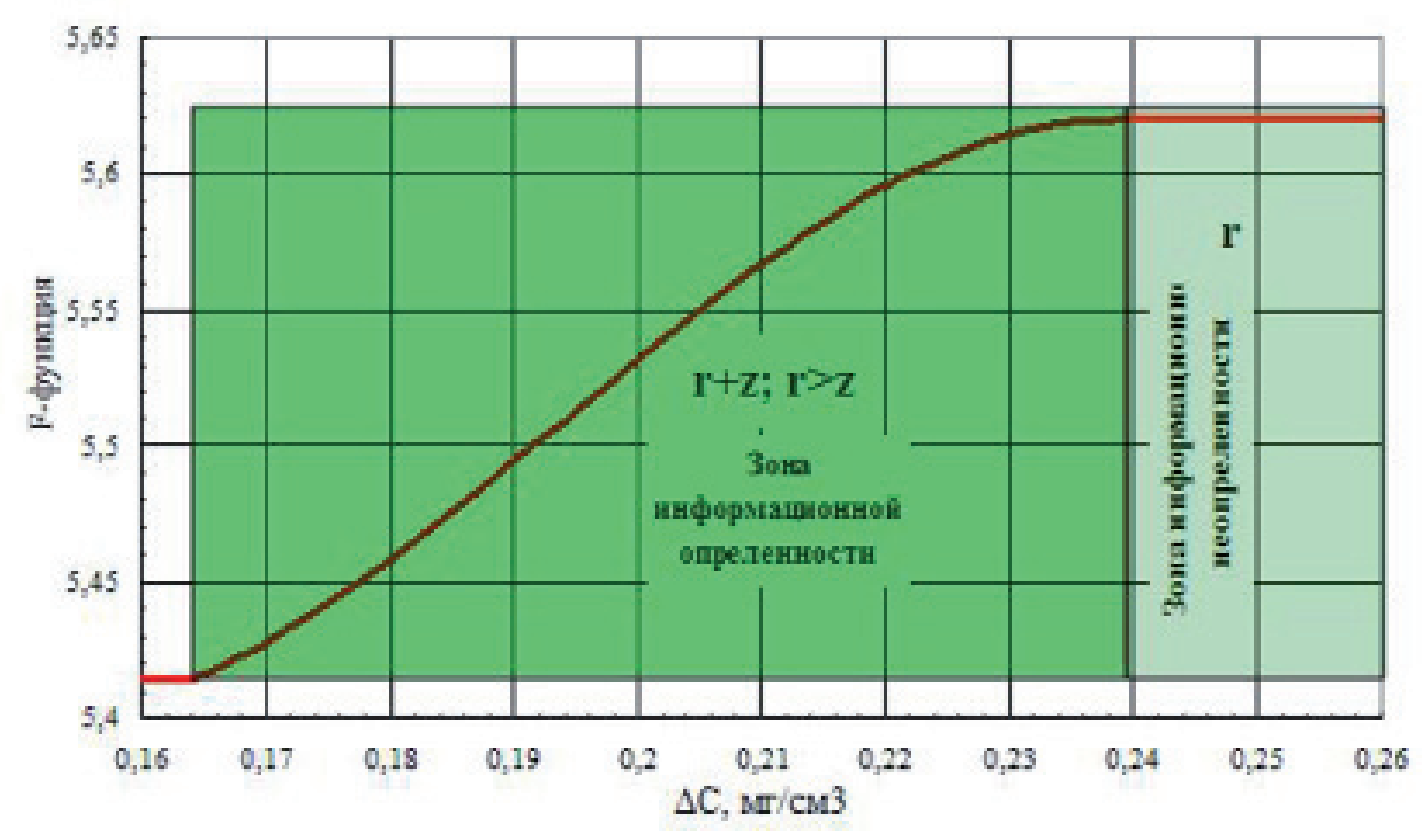

Рис. 8. Морфогенетическая диаграмма кристаллов квариа с приведенным удлинением призматического пояса 0.8 .

\section{Задача 1.}

Определить вероятный промежуток времени $(\tau)$, в течение которого рос гигантский кристалл кварца, добытый на Светлинском месторождении.

По данным Л.М. Петрухи [6] и Ю.А. Поленова [7] из хрусталеносной полости добыто два гигантских кристалла и много значительно меньших общим весом 16.6 т. R-кристалл «Юбилейный-1l» имел размер по оси $\mathrm{L}_{3} 1.6$ м, по коротким осям - 1.5 м. Кристалл кварца «Юбилейный-1» был несколько меньше. Они образованы преимущественно гранями основных ромбоэдров. Грани призмы развиты незначительно. Соотношение длины к ширине кристаллов, близкое к 1:1 Кристаллы содержали двухфазовые газово-жидкие включения с содержанием газа от 15 до 30 \%. Температура гомогенизации находится в пределах 262-290 ${ }^{\circ} \mathrm{C}$. Состав растворов во включениях бикарбонатно-хлоридно-натриевый.

Определим исходные данные для расчетов. Температура гомогенизации ГЖВ определяет нижний предел температуры кристаллизации кварца. Следовательно, принимаем $\mathrm{t}>290^{\circ} \mathrm{C}$. Состав минералообразующего раствора углекисло-водный с концентрацией солей в пересчете на соду 10 \%. На завершающем этапе отношение $v_{z} / v_{r} \approx 1$. Анатомическая картина роста кристалла не известна. Поэтому рассматриваем два варианта, определяющие верхний и нижний предел искомого промежутка времени: 1) $r_{z} / r_{r} \approx 1$ в течение всего времени роста кристалла; 2) $r_{z} / r_{r}=0$. Геометрические параметры кристалла: $1=1600 \mathrm{Mм}, \rho=51.79^{\circ}$. Температуру кристаллизации принимаем равной $300^{\circ} \mathrm{C}$.

Из кинематической схемы (рис. 1) и выражений (18) и (19) следует:

$$
\tau=\frac{l \operatorname{Cos} \rho}{v_{r}} ; \quad v_{r}=0.0026(\Delta C)^{1.4} ; \Delta C=\frac{v_{z}}{6,085 v_{r}} .
$$


Подставив третье выражение во второе, а затем второе в первое, получим искомую расчетную формулу

$$
\tau=\frac{l \operatorname{Cos} \rho}{0,0026\left(\frac{v_{z}}{6,085 v_{r}}\right) 1,4}
$$

Для приведения измерения в годах полученное выражение разделим на 365 и произведем замену переменной $v_{z} / v_{\mathrm{r}}$ на отношение площадей граней: $\mathrm{S}_{\mathrm{z}} / \mathrm{S}_{\mathrm{r}}$ (при обязательном условии равенства площадей всех граней каждого ромбоэдра). Для этого воспользуемся отношением:

$$
\begin{array}{lll}
v_{z} / v_{r}: & 1 & 1,446 \\
S_{z} / S_{r}: & 1 & 0
\end{array}
$$

Откуда получим линейное выражение новой переменной.

$$
\frac{v_{z}}{v_{r}}=1.446-0.446 \frac{S_{z}}{S_{r}}
$$

Поставив (26) в (25) и производя арифметические вычисления получим выражение зависимости продолжительности роста кристалла от его измеряемых морфологических параметров.

$$
\tau=\frac{0,6519 l}{\left(0,237-0,073 \frac{S_{z}}{S_{r}}\right) 1,4}
$$

Представим (27) в логарифмической форме и построим графики $\lg \tau=f(\lg l)$ для отношений $\mathrm{S}_{\mathrm{z}} / \mathrm{S}_{\mathrm{r}}$ от 0 до 1 (рис. 9)

$$
\lg \tau=\lg l-0,1858-1.4 \lg \left(0.237-0,073 \frac{S_{z}}{S_{r}}\right)
$$

Подставив в (28) параметры кристалла Юбилейный II: l=1600мм, $\mathrm{S}_{\mathrm{z}} / \mathrm{S}_{\mathrm{r}}=0$ и $\mathrm{S}_{\mathrm{z}} / \mathrm{S}_{\mathrm{r}}=1$, получим искомые пределы вероятной продолжительности его роста.

Вариант 1. $S_{z} / S_{r}=0, \lg \tau=3.89, \tau=7754$ или с округлением 8000 лет.

Вариант 2. $S_{z} / S_{r}=1, \lg \tau=4,113, \tau=12984$ или с округлением 13000 лет.

Поскольку корневая часть кристалла, сформировавшаяся в зоне геометрического отбора, была отломана, то полученные временные оценки необходимо увеличить примерно на треть: в первом варианте 10.4 тыс.лет, во втором 16.9 тыс. лет. Реальная продолжительность роста кристалла Юбилейный II находится в этом интервале, но вероятнее ближе к верхнему пределу, поскольку кристаллы с моноромбоэдрической головкой встречаются крайне редко. Из 16.6 т добытого из гнезда кристаллосырья около 7т приходится на два кристалла. Продолжительность формирования хрусталеносного гнезда можно отождествить с продолжительностью роста наиболее крупного кристалла Юбилейный II, или с округлением 17000 лет. Оценка продолжительности действия гидротермальной системы 
на Светлинском месторождении, полученная по морфологическим параметрам кристалла Юбилейный II, вписывается в интервал 0.01-1.9 млн. лет, определенный разными другими методами многими авторами для ряда рудообразующих гидротермальных систем [14].

Расчетную формулу (28) и графики (рис. 9) можно использовать для оценки продолжительности роста любых кристаллов кварца, не зависимо от их генезиса и условий образования. Из формулы (28) вытекает парадокс роста кристаллов кварца: гигантский кристалл типа Юбилейный II и кристалл такой же длины по $\mathrm{L}_{3}$, но толщиной с карандаш растут в течение равного промежутка времени. На качественном уровне этот вывод вытекает из тезиса 9. Это позволяет еще раз утверждать, что удлинение кристалла кварца можно использовать как типоморфный признак какого-либо месторождения или отдельного гнезда, но ни в коем случае его нельзя увязывать с физико-химическими условиями кристаллизации.

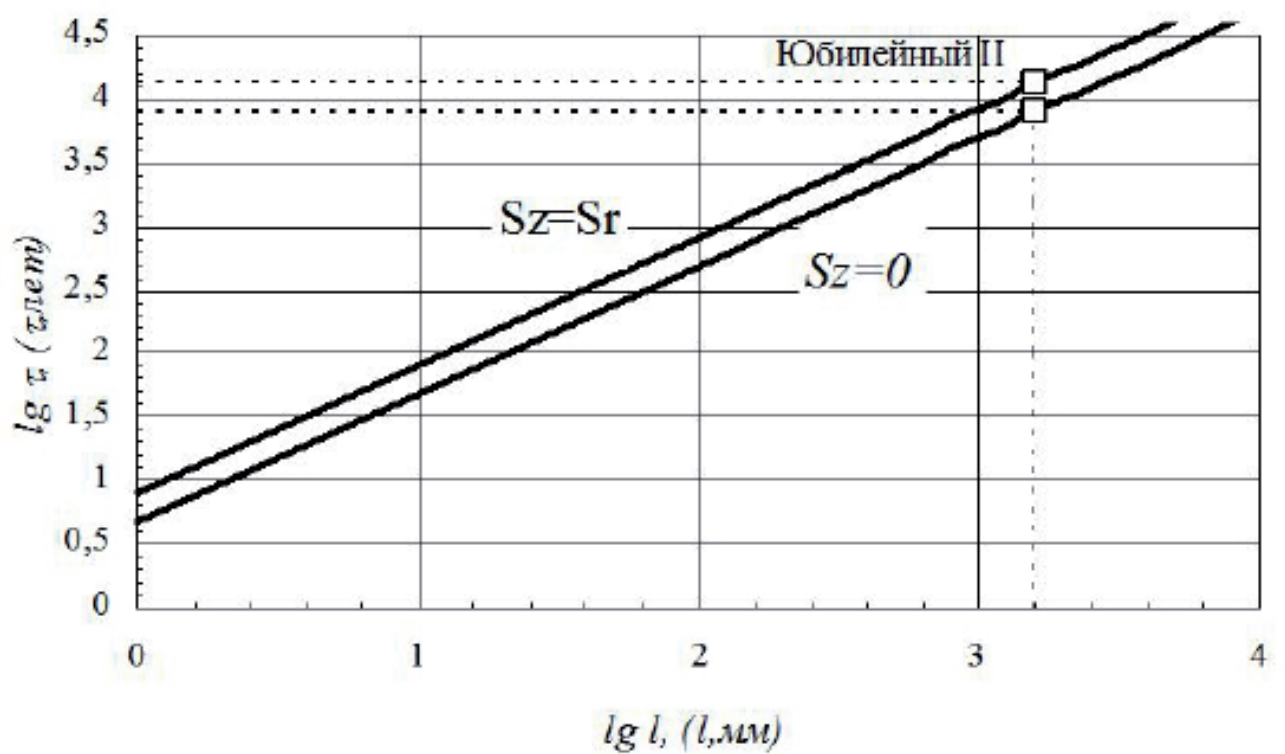

Рис. 9. Продолжительность роста кристаллов квариа в зависимости от полудлинь кристалла по $L_{3}$ (l) и соотномения площадей граней ромбоэдров z и r.

Задача 2.

Светлинское хрусталеносное месторождение приурочено к седловинной структуре, расположенной между тремя купольными структурами, образованными Санарским, Борисовским и Демаринским позднепалеозойскими гранитными массивами. Предполагается, что на глубине эти массивы образуют единое тело. Необходимо определить температуру в зоне растворения кремнезема, оценить геотермический градиент на момент образования хрустальной минерализации и глубину залегания кровли гранитного массива.

Температуру в зоне растворения определим по формуле (20), заменив в ней, как и в первой задаче, переменную по формуле (26).

$$
t_{1}=\left[t_{2}^{m}+0.16\left(\frac{v_{z}}{k v_{r}}\right)\right]^{\frac{1}{m}}=\left(t_{2}^{m}+0.16 \frac{1,446-0.446 \frac{S_{z}}{S_{r}}}{k}\right) \frac{1}{m}
$$


Расчет проведем также по двум вариантам: 1) $\left.S_{z} / S_{r}=0.2\right) S_{z} / S_{r}=1$

Исходные данные: $t_{2}=300^{\circ} \mathrm{C}$, из уравнения растворимости кремнезема в $10 \%$ растворе соды (рис. 7) имеем $k=2 * 10^{-5}, m=2.538$.

$$
\begin{aligned}
& t_{1}=\left(300^{2.538}+\frac{0.231-0.071 * 0}{2 * 10^{-5}}\right)^{\frac{1}{2.538}}=300.7^{0} \mathrm{C} \text { для } S_{z} / S_{r}=0 \\
& t_{1}=\left(300^{2.538}+\frac{0.231-0.071 * 1}{2 * 10^{-5}}\right)^{\frac{1}{2.538}}=300.5^{0} \mathrm{C} \text { для } S_{z} / S_{r}=1
\end{aligned}
$$

Геотермический градиент при допущении подчинения его линейному закону равен:

$$
\operatorname{grad} T=\frac{t_{1}-t_{2}}{h} 1000\left({ }^{0} \mathrm{C} / \kappa M\right)
$$

Особую сложность представляет определение параметра $h$. В первом приближении его можно оценить по полевой геологической документации. Однако нижняя граница окологнездовых изменений вмещающих пород обычно не четкая и визуально точно установить её невозможно. Более корректно эта задача реша-

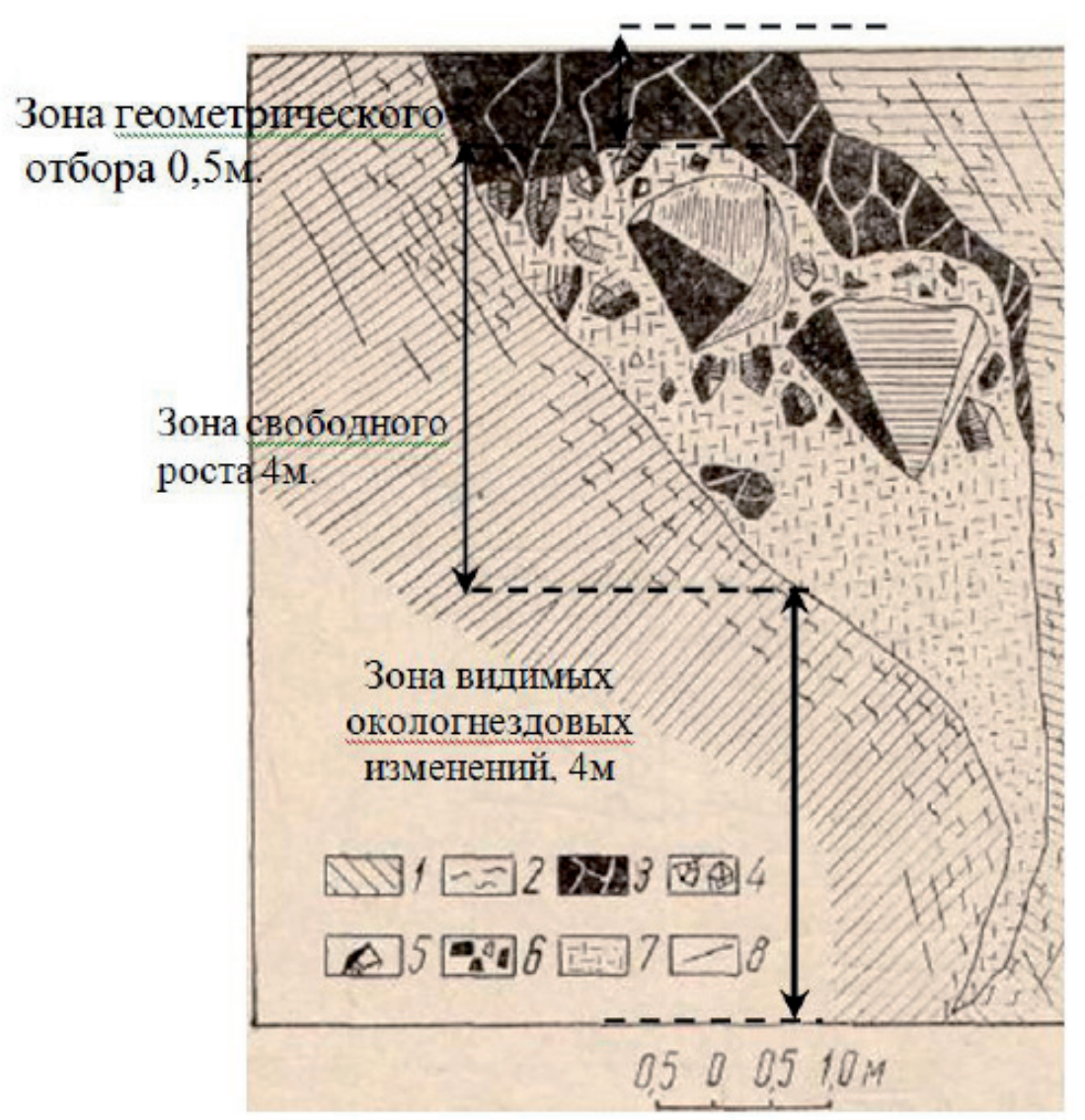

Рис. 10. Поперечный вертикальный разрез хрусталеносной полости.

1 - кристаллические сланцы; 2 - гидротермально измененные породы; 3 -жильный квари молочно-бельй, гигантозернистый, массивный; 4 - жильный квари стекловидный, шестоватый; 5 - кристаллы горного хрусталя; 6 - обломки жильного квариа; 7 - глинисто-слюдистый материал гнездового выполнения; 8 - трещиины. 
ется химическим анализом проб, отобранных по профилю на разных расстояниях от гнезда с обязательным комплексированием с петрографическими исследованиями. К сожалению, геологами эти условия не всегда выполняются. В нашем случае воспользуемся зарисовкой хрусталеносного гнезда жилы 500, опубликованной Л.М. Петрухой [5] (рис. 10).

Задачу нахождения параметра $h$ решим в одномерном варианте. Для этого на разрезе выделим сверху вниз следующие зоны: 1) геометрического отбора, 2)свободного роста. 3) видимых окологнздовых изменений. Первые две из них являются зонами роста кварца, третья - зоной его растворения. Условно от верхней границы зоны геометрического отбора вертикально вниз через все зоны выделим колонну сечением $1 \mathrm{~m}^{2}$ и составим для этой колонны баланс кремнезема.

$$
m_{s}=m_{k}
$$

где $m_{s}$ и $m_{k}-$ масса соответственно растворившегося и выкристаллизовавшегося кремнезема.

В нашем распоряжении имеются лишь два химических анализа вмещающих пород. Один из них фоновый, а второй выполнен по пробе, отобранной вблизи гнезда. По расчетам Л.М. Петрухи вынос (вернее сказать интенсивность выноса в точке отбора пробы - авт.) кремнезема составил 300 кг/м³. Интенсивность «привноса-выноса» массы, энергии в любых системах можно описать экспоненциальной функцией

$$
-\frac{d m}{d x}=a e^{k x}
$$

Проинтегрировав уравнение (32) в пределах от 0 до некоторой величины (глубины) h, получим выражение массы растворившегося кремнезема.

$$
m_{S}=a \int_{0}^{h} e^{k x} d x=\left.\frac{a}{k} e^{k x}\right|_{0} ^{h}=\frac{a}{k}\left(e^{k h}-1\right) .
$$

Для строго математического расчета констант в уравнениях (32) и (33) недостаточно одного анализа метасоматически измененных пород. Допустим, что на нижней границе зоны видимых изменений (4 м от гнезда) интенсивность выноса кремнезема в сравнении с выносом вблизи гнезда $(1 \mathrm{~m})$, уменьшается в два раза

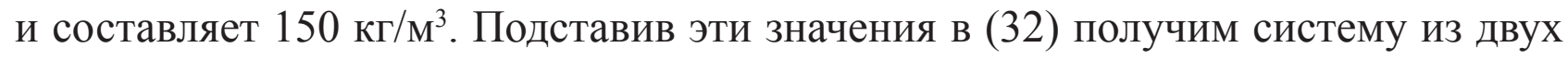
уравнений с двумя неизвестными ( $a$ и $k$ ).

$$
\mid \begin{aligned}
-300 & =a e^{k} \\
-150 & =a e^{4 k}
\end{aligned}
$$

Знак минус в (34) означает, что процесс идет с выносом вещества из системы. Разделив первое уравнение на второе и прологарифмировав полученное выражение определим числовое значение константы $k=\ln 2 / 3=-0.231$. Подставив $k$ в одно из уравнений (34) найдем второе неизвестное: $a=378$. Далее подста- 
вив найденные константы в (33) получим формулу для определения количества кремнезема, вынесенного в полость при продвижении фронта гидротермального изменения вмещающих пород на расстояние 1 от гнезда.

$$
m_{s}=\frac{378}{0,231}\left(e^{k l}-1\right) \approx 1636\left(1-e^{-0.231 l}\right)
$$

Количество выкристаллизовавшегося кремнезема в колонне сечением $1 \mathrm{M}^{2}$ состоит из кварца зоны геометрического отбора $\left(m_{1}\right)$ и кристаллов кварца $\left(m_{2}\right)$.

$$
m_{k}=m_{1}+m_{2}=d h_{1}+P / S=2600 * 0.5+16600 / 35=1774(\kappa 2)
$$

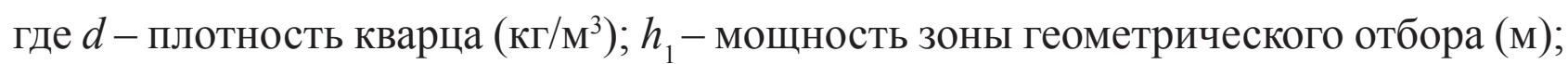
$P$ - вес добытых кристаллов (кг); $S$ - площадь нарастания кристаллов, определяемая из клиновидной формы полости, её высоты (4 м) и объема (70 м³).

Подставив (35) и (36) в (31) получим выражение баланса кремнезема в рассматриваемой системе

$$
1774=1636\left(1-e^{-0.231 l}\right)
$$

откуда путем логарифмирования находим 1.

$$
l=-\ln (1774 / 1636-1) / 0.231=10.7(\mathrm{M})
$$

Среднее расстояние между зонами растворения и роста кварца $(h)$ определим как сумму полумощностей зон растворения и роста: $h=(10.7+4+0.5) / 2=7.6 \mathrm{м}$. Подставив его в (30) решим задачу оценки геотермического градиента для двух предельных вариантов.

$$
\begin{aligned}
& \text { Вариант1. } S_{z} / S_{r}=0 \operatorname{grad} T=\frac{300.7-300}{7.6} 1000=92\left({ }^{0} \mathrm{C} / \mathrm{\kappa m}\right) \\
& \text { Вариант2. } S_{z} / S_{r}=1 \operatorname{grad} T=\frac{300.5-300}{7.6} 1000=66\left({ }^{0} \mathrm{C} / \mathrm{kM}\right)
\end{aligned}
$$

Обе оценки палеотермального градиента находятся в интервале измеряемых значений этого параметра в термоактивных областях [14]. Однако в соответствии с тезисом 9 реальное значение палеоградиента на момент образования Светлинского месторождения более близко к $66^{\circ} \mathrm{C} / к м$. Аномально высокий палеотермический градиент свидетельствует о существовании на момент образования Светлинского месторождения возмущающего теплового источника, которым мог бы быть остывающий гранитный массив (тезис 1).

Далее определим глубину $(H)$ залегания кровли гранитного массива, предположив, что температура $\left(\mathrm{t}_{0}\right)$ его поверхности на время развития хрусталеносной минерализации остыла до $500^{\circ} \mathrm{C}$.

$$
H=\frac{t_{0}-t_{1}}{\operatorname{grad} T}=\frac{500-300}{66} \approx 3(\kappa \mathrm{k})
$$

По гравиметрическим данным в центральной части месторождения глубина залегания гранитного массива оценивается в 3-3.5 км. 
В заключение следует отметить, что все оценки геологических параметров гидротермальной системы Светлинского месторождения получены в условиях неполноты исходной информации, потому носят приблизительный характер. Вышеприведенные примеры преследовали цель продемонстрировать возможности разрабатываемого автором метода морфокинетического анализа кристаллов кварца. Этот метод в равной степени применим и к рудным месторождениям, в которых кристаллы кварца встречаются в парагенезисе с целевыми минералами.

Автор приносит искреннюю благодарность профессорам Уральского горного университета С.Г. Паняку, В.Н. Огородникову, Ю.А. Поленову, а также к.г.-м.н. Г.И. Крыловой за помощь в выполнении данной работы.

\section{Список литературы}

1. Бакли Г. Рост кристаллов. М.: ИЛ, 1954.

2. Балицкий В.С. Экспериментальное изучение геохимических условий формирования кристаллов кварца. М., 1971.

3. Бутузов В.П., Брятов Л.В. К вопросу о выращивании кристаллов кварца. Рост кристаллов. М., 1967.

4. Дэна Дж., Дэна Э.С., Фрондель К. Система минералогии. Минералы кремнезема. М.: МИР, 1966.

5. Петруха Л.М., Хохлачев А.П. Измененные окологнездовые породы месторождения горного хрусталя Южного Урала. Тр. СГИ «Минералогия и петрография». Вып. 106. Свердловск, 1975. С. 67-71.

6. Петруха Л.М. Гигантские кристаллы горного хрусталя на Южном Урале // Горный журнал. № 8. 1995. Свердловск. С. 150-155.

7. Поленов Ю.А. Эндогенные кварцево-жильные образования Урала. Издво: Уральского горного университета. Екатеринбург, 2008.

8. Продолжительность процесса минералообразования, сайт.

9. Страшненко Г.И. Теоретическое обоснование интегрального количественного показателя формы кристаллов // Тр. XI Bсерос. (с межд. участием) научн. школы «Математ. исслед. в естественных науках». Апатиты, 11-12 нояб. 2014 г. Апатиты: Изд-во К \& M, 2014. С. 48-120.

10. Страшненко Г.И. Равновесная форма кристаллов средних и низших категорий симметрии при бесконечно малых пересыщениях // Tp. XIII Bcepoc. (с межд. участием) научн. школы «Математ. исслед. в естественных науках». Апатиты, 17-18 окт. 2016 г. Апатиты: Изд-во К \& M, 2016. С. 85-96.

11. Страшненко Г.И. Морфометрия и морфогенез кристаллов. Saarbrucen, Deutschland. LAMBERT Acad. Puabl., 2016.

12. Страшненко Г.И. Морфометрический анализ сложных комбинационных форм тригональной сингонии. В данном сборнике.

13. Стрикленд-Констэбл Р.Ф. Кинетика и механизм кристаллизации. «Недра», Ленинград, 1971.

14. Burrus R.C., Hollister L.S. Evidence from fluid inclusions for a paleogeothermal gradient at the geothermal test well sites / Los Alamos, New 